\title{
A Smart Approach to Measuring the Performance-Efficiency, Effectiveness and Productivity - of the General University Hospital of Alexandroupolis-G.U.H.A. using Special Indicators
}

\author{
E. Stathakis ${ }^{1}$, K. Brachos ${ }^{2, *}$, Ch. Abatzianis ${ }^{2}$, D. V. Bandekas ${ }^{2}$ and S. G. Mouroutsos \\ ${ }^{I}$ Dept. of Economical Sciences, Democritus University of Thrace, Komotini, Greece \\ ${ }^{2}$ Dept. of Electrical Engineering, Eastern Macedonia and Thrace Institute of Technology, Kavala, Greece \\ ${ }^{3}$ Dept. of Electrical and Computer Engineering, Democritus University of Thrace, Xanthi, 67100, Greece
}

Received 16 September 2016; Accepted 12 April 2017

\begin{abstract}
The purpose of this paper is to measure the performance of the General University Hospital of Alexandroupolis, as it is expressed by the technical and economic parameters. It is examined, via 3 smart managerial tools and mainly through 8 well-structured indicators. Although the benchmarking is a very useful managerial tool in comparative basis, we avoided to use it to this paper, because it needs numerous data for 9 Greek university hospitals. The authors concluded that: The present situation of the hospital does not correspond to the existed resources spent, in qualitative and quantitative basis. The 4 indicators from 8, measuring hospital's efficiency, effectiveness and productivity, are marginally good, and they could be upgraded/ improved, through modern managerial tools specialized for health organizations. The other 4 are satisfactory. The already MIS has some drawbacks and it has to be upgraded in a smart way. Human resources and biomedical equipment also needed renewal.
\end{abstract}

Keywords: health care unit, efficiency, effectiveness, productivity, innovation

\section{Introduction}

In Greece, like the most E.U. countries, the matter of health care provision raises debates which have often led to a series of reforms up to this day [1]. Despite the technological progress and the quantitative and qualitative upgrade of the Greek health care system during the last decades, the patient's satisfaction from the services remains low. Many similar problems there are in other European countries as Ireland as conclusion by similar analysis testing [2]. The total of society would expect much more qualitative health services since they have spent grey amount of resources. An entire separate study could focus on the "patient's expectations" from an effective medical system and from the level of satisfaction, until the costing for provisions of health care and medical treatment that consists of special services for people[3]. Also according literature [4] through the measurement of its efficiency a health system can be reached the quality and the quantity of the health services provided.

For all that mentioned above we consider very important to investigate the efficiency, the effectiveness and the productivity of a representative health unit providing health services and more certain a university public Hospital in Greece as has been done in other countries [5], and why its health services provided to patients' are not so qualitative and therefore, their expectations are not so good. Moreover, this work focus and examines on the basic factors of hospital

"E-mail address: kostasbrahos@yahoo.gr

ISSN: 1791-2377 @ 2017 Eastern Macedonia and Thrace Institute of Technology. All rights reserved. competitiveness,[6] eg effectiveness, efficiency and productivity [7], of the hospital by using essential strategic management tools such as, special indicators, SWOT analysis [8] and Porter's competitive forces model[9]. We chose GUHA as a research sample for three reasons, for its adequate size -500 beds, for its regionality and for its ability to recover all medical sectors. Also they have been chosen effectiveness, efficiency and productivity as measures of hospitals competitiveness because they include economic and technical data and information. Of course international bibliography helped us to understand much better what competitiveness means for a health organization and how it can be measured. But to this paper our innovative approach, is the new structure of special indicators used to saw how cost effective operates a hospital, new approach in SWOT analysis and Porter's model. For instance a divisional input- output approach gave us information regarding the performance differences among hospital divisions. Even, the paper provides practical recommendations for enhancing innovation initiatives and networking activities.

Finally, considering all the above, examine how GUHA can utilize more efficiently its resources and combine them with several operational planning tools in order to improve the quality of the offered hospital services, and become more patient-centered from medical-centered, leading thus to better financial results by reduction nursing costs per patient. Hence, the findings of this paper will attempt to help the top management of GUHA to gain further economic benefits coming by increase rate of return. 


\section{Method used.}

Our method based on numerous data and information, well classified and grouped in special indicators. The numerous data and information came from two sources.

Firstly from field research is based on interviews given by hospital insiders. Secondly from desk research, e.g. data and internal information collected from the G.U.H.A. . It should be noted that all the gathered data referred to year 2013.

The measurement of efficiency, effectiveness and productivity has been done by elaborating and analyzing data collected by hospital for its own use and by grouped and presented as indicators [10]. More certain, such indicators take firstly mathematical forms and then adapted properly per hospital sector and clinical department. Although, our model or method seems to be simple, besides, the great number of indicators, their proper grouping and the great number of technoeconomic fields that cover, give them an innovative perspective [11]

2.1 The concepts of efficiency, effectiveness and productivity and their mathematical forms

A field research was conducted based on interviews given by hospital insiders. Additionally, secondary data and internal information coming from the G.U.H.A. It should be noted that all the gathered data referred to 2013 .

The concepts of "effectiveness" (form 1), and "productivity" (form 2), are closely linked with the concept of "efficiency". They are both methods for measurement and evaluation of production units, organizations, or systems. In order to draw safe conclusions concerning the efficient operation of the production units, organizations, or systems, the measurement outputs of the productivity and effectiveness must be separated by the data which describe the wider productive environment. Effectiveness is a factor showing how effective is a system in techno-economic.

Through effectiveness the output of health services or in this specific case of a health system are evaluated in terms of economical, technical, technological and human resources basis. Effectiveness describes also the ability of a production unit to efficiently transform its input in output through minimizing the cost. There are some forms of effectiveness. As it is stated [12] in the literature there are several management tools which have been developed for evaluating measuring and analyzing the productivity and the efficiency of production units organizations, or systems.

As we can see in equation 1 a health service providing unit which uses a great number of "inputs", for example medical experts, capital, medical equipment, buildings etc., in order to produce a final special and measurable service called "output". The analysis of efficiency is defined as the measurement of the capability of production unit to transform the inputs to outputs.

The mathematical formula of effectiveness is the bellow:

E. $\mathrm{R}=\mathrm{ACG}_{\mathrm{ODL}} \div \mathrm{ACG}_{\mathrm{C}}$

Where,

$\mathrm{ER}=$ effectiveness ratio

$\mathrm{ACG}_{\mathrm{ODL}}=$ average cost per patient

$\mathrm{ACG}_{\mathrm{C}}=$ average cost per clinic unit
Efficiency: Efficiency is a factor showing how effective is a system in pure economic basis. This parameter is measured by different kind of indicators as: a) Pure economic efficiency, b) Scale efficiency, c) Allocative or price efficiency, and d) Overall (or cost) efficiency.

Productivity: Productivity is called the quotient of the result of a production process through the inputs used to it. Mathematically takes the formula:

Productivity $=$ Outputs/inputs.

2.2 Presentation of certain indicators measuring the efficiency, effectiveness and productivity of a university hospital

There are several academic studies regarding the analysis and measurement of the determining factors of efficiency of health systems. In most of these studies, researchers focus in the efficient utilization of the available resources of hospitals in order to improve their overall performance [13]. Adds that this strategy constitutes the primary objective of almost all of the countries members of OECD $[14,15]$.

In any case, indicators are a necessary assessment tool/method due to give a clear picture regarding the total performance of a health unit and its special techno-economic structure and the measurement outputs become more comprehensible since they can be expressed without problems concerning the variable of time [16].

The classification criteria for indicators are: adequacy, effectiveness, efficiency and productivity. Essentially, the indices are the simplest way of expression of the concepts that this project attempts to examine.

\subsection{Conclusions on general and theoretical part}

It is very important to measure the effectiveness of a health organization, like G.U.H.A., with adhoc indicators, by collecting, classifying and elaborating technical and economic data that reflect significant correlations that are more useful than the simple juxtaposition of data. The indicators through ratios, can give the real image of the body whose we measure its performance, etc. Four general principles for indicators used to measure health organizations performance: a) they must clearly measure the defined object, b) they provide to all investigators the same result and under different conditions, c) they reflect all of the changes of the phenomenon under study, and d) they react solely to the changes related to the phenomenon .

So, the indicators suggested are based on, the prerequisites of validity, the objectivity, the sensitivity and the expertise according to the four principals of Souliotis [17]. To the next, the indicators suggested measured and evaluated.

\subsection{Concretizing our method to measure hospital's performance}

They have been used 3 estimation tools in order to measure the performance- efficiency, effectiveness and productivity- of the GUHA in a simple but very precise way.

The first tool used is the 8 adhoc indicators that were created by numerous data and information collected by us through special desk research. The other 2 welladapted managerial tools were SWOT analysis and Porter's 5 forces model. To the next it will be presented in details the 3 managerial tools. 
2.5 First tool: Using 8 special indicators

2.5.A. Some basic information and data showing Hospital's structure, size and treatment capabilities The hospital of Alexandroupolis is built in a beautiful area, distancing only $5 \mathrm{~km}$ from Alexandroupolis. It covers $93.544 \mathrm{M} 2$ in 3 stores and its total capacity is 671 beds, but full in use are only 500 .

The main hospital's objectives are: to offer health care in all levels, primary, secondary and tertiary, for many sophisticated medical specializations. This fact shows the vital role of GUHA, as it is due to the number of departments and its well experienced and skillful staff, which facilitate several incidents in northeastern Greece that cannot be treated somewhere else.

The average number of employees was 1277 (2013). The table 1 illustrates the number of employees per month, whereas figure 1 describes their specializations in seven main groups. The existed small monthly differences due to some of personnel work in provisional basis.

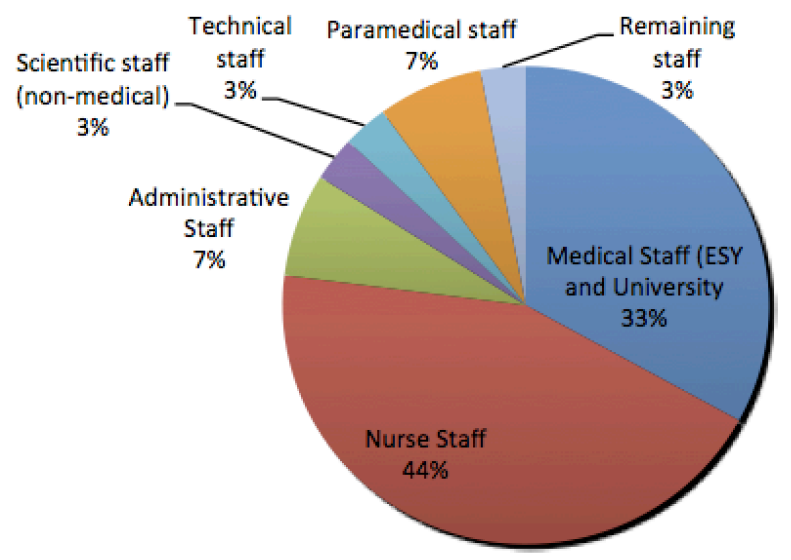

Fig.1. Employees per specialty in G.U.H.A, 2013

Table 1. The number of employees per month

\begin{tabular}{cc}
\hline January & 1304 \\
February & 1290 \\
March & 1261 \\
April & 1290 \\
May & 1287 \\
June & 1285 \\
July & 1285 \\
August & 1279 \\
September & 1267 \\
October & 1257 \\
November & 1250 \\
December & 1243 \\
\hline Mean & $\mathbf{1 2 7 3 , 3}$ \\
\hline
\end{tabular}

2.5.B. Indicators measuring/estimating efficiency, effectiveness and productivity of G.U.H.A.

A number of carefully chosen and well-structured indicators have been used to give a very concise, realistic and representative picture of hospital's performance.

$\mathbf{1}^{\text {st }}$ Indicator: Structure and quality of human resources. This indicator consists from 11 components that are very relevant to certain indicator.
Table 2 shows the ratios/relations among the categories of employees and beds in G.U.H.A, while table 3 shows the ratios/ relations among the different categories of employees between them.

Table 2. Quantitative analysis of the ratios between the categories of employees and beds (Quantitative relationships)

\begin{tabular}{ll}
\hline Categories & $\mathbf{2 0 1 3}$ \\
\hline Total of employees $/$ bed & $1277 / 500=\mathbf{2 , 5 5}$ \\
Total of medical staff / bed & $414 / 500=\mathbf{0 , 8 2}$ \\
Total of nursing staff / bed & $578 / 500=\mathbf{1 , 1 5}$ \\
Total of administrative staff / bed & $88 / 500=\mathbf{0 , 1 7}$ \\
Total of scientific staff / bed & $35 / 500=\mathbf{0 , 0 7}$ \\
Total of technical staff / bed & $33 / 500=\mathbf{0 , 0 6}$ \\
Total of paramedical staff $/$ bed & $91 / 500=\mathbf{0 , 1 8}$ \\
Total of remaining staff / bed & $36 / 500=\mathbf{0 , 0 7}$ \\
\hline
\end{tabular}

Table3. Qualitative analysis of the ratios between the different categories of employees and beds (qualitative relationship)

\begin{tabular}{ll}
\hline Categories & $\mathbf{2 0 1 3}$ \\
\hline Doctors / total staff & $414 / 1277=\mathbf{3 2 , 4 2} \%$ \\
Nurses / total staff & $578 / 1277=\mathbf{4 5 , 2 6} \%$ \\
Nurses / doctor & $578 / 414=\mathbf{1 , 3 9}$ \\
\hline
\end{tabular}

$\underline{2}^{\text {nd }}$ Indicator: beds distribution per medical sector This indicator shows how the total 500 beds are distributed among medical sectors and if this distribution is normal, symmetrical and effective. It is consists of 4 components.

It's clearly that the pathology and the surgical divisions utilize most of the hospital's total resources, since they occupy $235(47 \%)$ and $212(42,40 \%)$ beds respectively (table 4).

Table 4. Summary table of number of beds per division

\begin{tabular}{lll}
\hline Total of beds & $\mathbf{5 0 0}$ & $\mathbf{1 0 0 \%}$ \\
\hline Pathology Unit Total of Beds & 235 & $47 \%$ \\
Surgical Unit Total of Beds & 212 & $42,40 \%$ \\
Psychiatry Unit Total of Beds & 22 & $4,40 \%$ \\
Remaining units total number of beds & 31 & $6,20 \%$ \\
\hline
\end{tabular}

$3^{\text {rd }}$ Indicator: economic outputs and performance this indicator consists from 5 components that are very important to certain indicator. (Table 5)

Table 5. Output and operational efficiency indicators of G.U.H.A.

\begin{tabular}{ll}
\hline Operational output indicators & \\
\hline Total days of hospitalization & 129.244 \\
Total admissions - inpatients & 42.423 \\
Number of laboratory work and examinations & 2.435 .089 \\
Number of surgical and endoscopic operations & 11.354 \\
Number of visits of outpatient clinics & 102.845 \\
\hline
\end{tabular}




\section{$4^{\text {th }}$ Indicator: operation efficiency}

This indicator consists from 6 components that are very relevant to certain indicator. It's about the length stay per hospital sector (Table 6).

Table 6. Operational efficiency indicators of G.U.H.A.Occupancy (Average Bed occupancy) \%

\begin{tabular}{ll} 
Average length of stay & 3,04 \\
ADS pathology & 2,7 \\
ADS surgery & 3,01 \\
ADS psychiatry & 11,77 \\
ADS of other units & 3,97 \\
\hline
\end{tabular}

$5^{\text {th }}$ Indicator: the basic component of productivity

This Indicator measuring express the factors of economic effectiveness, aiming at improving the quality of services offered to patients. They include indicators measuring the hospitalization days per employee, or show the treatment cost per employee. In table 7, the basic components of certain indicator reveal the relations among, total days of hospitalization, category of staff occupied, and relevant divisions.

Table 7. Basic components of $5^{\text {th }}$ indicator

\begin{tabular}{ll} 
Total hospitalization days / employee & 101,2 \\
Total hospitalization days / doctor & 312,18 \\
Total hospitalization days / nurse & 223,6 \\
Admissions - inpatients / bed & 84,84 \\
Admissions - inpatients /employee & 33,22 \\
Surgical operations /doctor & 27,42 \\
\hline
\end{tabular}

\section{$6^{\text {th }}$ Indicator: structure of operational expenditure}

This indicator consists from 7 components (table 7) based in data from table 8 that are very relevant to certain indicator.

Table 8. Total operational cost (without employee's wages)

\begin{tabular}{lccc}
\hline Month & Fixed cost & Variable cost & Total cost \\
\hline & & & \\
January & 254.697 & 1.972 .413 & 2.227 .110 \\
February & 1.049 .106 & 4.057 .254 & 3.816 .038 \\
March & 1.941 .022 & 5.999 .332 & -4.703 .646 \\
April & 2.045 .896 & 8.712 .548 & -1.944 .129 \\
May & 2.834 .783 & 10.303 .150 & 2.577 .933 \\
June & 3.057 .968 & 12.414 .709 & 5.710 .918 \\
July & 3.516 .027 & 14.776 .882 & 2.724 .349 \\
August & 4.049 .947 & 16.267 .151 & 8.018 .183 \\
September & 4.339 .708 & 17.540 .664 & 15.248 .662 \\
October & $4.797 .598,42$ & 19.490 .740 & $14.592 .418,42$ \\
November & 5.265 .370 & 21.606 .850 & 21.751 .263 \\
December & $5.977 .787,77$ & 22.827 .202 & $25.457 .176,07$ \\
\hline
\end{tabular}

$7^{\text {th }}$ Indicator: quantitative relations between personnel and operational cost

This indicator consists from 2 basic components, personnel and operational cost (table 10) and also by regular monthly wage and special wage (tables 9 and 10) and is very relevant to certain indicator.

Table 9. Regular monthly wages in G.U.H.A. (2013)

$\begin{array}{ccc}\text { January } & 1.444 .499,87 & 1.001 \\ \text { February } & 1.442 .775,25 & 971 \\ \text { March } & 1.432 .252,49 & 960 \\ \text { April } & 1.633 .671,69 & 965 \\ \text { May } & 1.560 .705,13 & 965 \\ \text { June } & 1.537 .503,57 & 960 \\ \text { July } & 1.615 .054,32 & 951 \\ \text { August } & 1.575 .549,31 & 944 \\ \text { September } & 1.636 .846,15 & 937 \\ \text { October } & 1.633 .376,63 & 935 \\ \text { November } & 1.619 .703,30 & 923 \\ \text { December } & 1.693 .360,72 & 920 \\ \text { Year total } & \mathbf{1 8 . 8 2 5 . 2 9 8 , 4 3} & \end{array}$

Table 10. Special allowances to the employees of G.U.H.A (2013)

\begin{tabular}{ccc}
\hline Month & $\begin{array}{c}\text { Special wage } \\
\text { regime }\end{array}$ & $\begin{array}{c}\text { Number of } \\
\text { employees }\end{array}$ \\
\hline January & $828.852,18$ & \\
February & $611.953,81$ & 542 \\
March & $911.432,67$ & 337 \\
April & $1.707 .151,00$ & 455 \\
May & $989.997,81$ & 440 \\
June & $1.068 .735,67$ & 446 \\
July & $984.601,21$ & 453 \\
August & $1.192 .416,06$ & 434 \\
September & $1.236 .708,63$ & 435 \\
October & $1.298 .787,05$ & 448 \\
November & $1.223 .740,08$ & 442 \\
December & $1.633 .968,51$ & 428 \\
\hline Year & & 437 \\
total & $\mathbf{1 3 . 6 8 8 . 3 4 4 , 6 8}$ & \\
\hline
\end{tabular}

$8^{\text {th }}$ indicator: Monthly divisional patient inflows

Figure 2, show the patients flow in the emergency units (TEP), the Regular Outpatient Clinics (TEI) and the daylongs flow (afternoon outpatient clinics) for each month. Consists of 3 components (the 3 clinics) and are very relevant to certain indicator (table 11).

Table 11. Patients flow per month.

\begin{tabular}{ccccc}
\hline Month & $\begin{array}{c}\text { Patients } \\
\text { examined in } \\
\text { TEI }\end{array}$ & $\begin{array}{c}\text { Number } \\
\text { of } \\
\text { patients } \\
\text { examine } \\
\text { d in } \\
\text { TEP }\end{array}$ & $\begin{array}{c}\text { Daylon } \\
\text { g flow }\end{array}$ & $\begin{array}{c}\text { Total } \\
\text { Patients } \\
\text { examin } \\
\text { ed }\end{array}$ \\
January & 9.139 & 3.795 & 520 & 13.454 \\
February & 9.424 & 3.954 & 451 & 13.829 \\
March & 9.145 & 4.579 & 416 & 14.140 \\
April & 9.981 & 4.157 & 515 & 14.653 \\
May & 7.956 & 4.314 & 432 & 12.702 \\
June & 9.294 & 4.413 & 460 & 14.167 \\
July & 9.715 & 4.513 & 475 & 14.703 \\
August & 7.189 & 4.335 & 239 & 11.763 \\
September & 9.561 & 4.025 & 607 & 14.193 \\
October & 10.059 & 3.969 & 532 & 14.560 \\
November & 4.029 & 9.690 & 546 & 14.265 \\
December & 7.353 & 3.683 & 360 & 11.396 \\
Year Total & $\mathbf{1 0 2 . 8 4 5}$ & $\mathbf{5 5 . 4 2 7}$ & $\mathbf{5 . 5 5 4}$ & $\mathbf{1 6 3 . 8 2 6}$ \\
& & & & \\
Mean & $\mathbf{8 . 5 7 0}$ & $\mathbf{4 . 6 1 9}$ & $\mathbf{4 6 2 , 7 5}$ & $\mathbf{1 3 . 6 5 2}$ \\
\hline
\end{tabular}




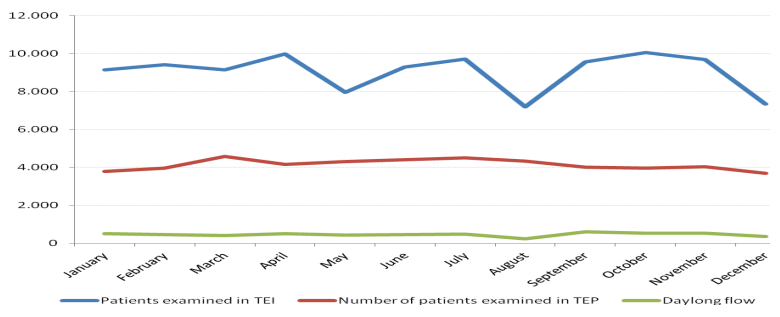

Fig. 2 Inflows in emergency department, in outpatient daylong clinics and in outpatient clinics

Figure 3 shows one innovative indicator, which expresses the relationship for monthly patients flow between morning regular outpatient clinics and daylong regular outpatient clinics.

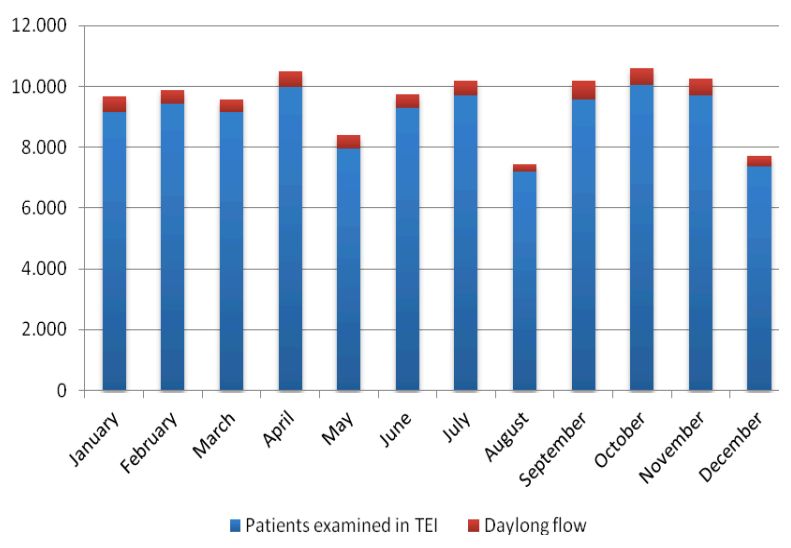

Fig. 3. Dynamic indicators between outpatient and daylong clinics.

Remark: The cost of the permanent staff of the G.U.H.A. is paid partially by the hospital and partially by the state. So, it doesn't burden $100 \%$ of the hospital's annual budget. The fuel, the food, the medication and the hygiene material costs, are shown individually, as ratios of the total cost.

\subsection{Ranking indicators using their marking and coefficient of gravity}

In order to mark the hospitals' final performance will suggest the next marking and the respective coefficients of gravity per indicator.

Of course, the maximum marks could be 100, and the outcome of 74 marks means that the GUHA gains a $74 \%$ of excellence (table 12).

Table12. Indicators

\begin{tabular}{|c|c|c|c|}
\hline Indicators & $\begin{array}{l}\text { Average } \\
\text { mark of } \\
\text { indicator } \\
1-10\end{array}$ & $\begin{array}{l}\text { Coefficient } \\
\text { gravity 1- } \\
10\end{array}$ & $\begin{array}{l}\text { Final } \\
\text { marks }\end{array}$ \\
\hline $\begin{array}{l}\text { 1.Structure and quality of } \\
\text { human resources }\end{array}$ & 8,5 & 1,6 & 13,6 \\
\hline 2.Beds performance & 6,8 & 1,0 & 6,8 \\
\hline 3. Operational efficiency & 7,8 & 1,2 & 9,4 \\
\hline $\begin{array}{l}\text { 4.Economic outputs and } \\
\text { performance }\end{array}$ & 7,5 & 1,5 & 11,3 \\
\hline $\begin{array}{l}\text { 5. Basic component of } \\
\text { productivity }\end{array}$ & 7,2 & 1,5 & 10,8 \\
\hline $\begin{array}{l}\text { 6.Structure of operational } \\
\text { expenditure }\end{array}$ & 8,0 & 1,0 & 8,0 \\
\hline $\begin{array}{l}\text { 7. Quantitative relations } \\
\text { between personnel and } \\
\text { operational cost }\end{array}$ & 7,6 & 0,6 & 4,6 \\
\hline $\begin{array}{l}\text { Monthly divisional patient } \\
\text { inflows }\end{array}$ & 9,5 & 1,0 & 9,5 \\
\hline
\end{tabular}

\section{Presentation of results}

3.1-regarding the issue of measuring GUHA's performance through indicators

1. The greater cost is the variable one and it is referred to the purchasing of drugs, hygiene and other similar materials. Energy and fuel supply cost, is also relatively high, whereas food cost is moved in mean levels.

2. The structure of overall operational cost-fix/variable and components of fix and variable is a very interesting issue. Alike, the break even point is $95,4 \%$ and it means that some costs have to be limited.

3. The fixed cost includes: the monthly operational expenses which include, electricity, cleaning, telecommunications, fuels, maintenance and reparations of the medical devices, machines, etc. It contributes about $62,3 \%$ to total cost.

4.The variable cost includes, the basic medical material and consumables, reagents, hygiene material, medication, clothing, food, drinks, etc. It contributes about $37,7 \%$ to total cost.

5. The best method measuring the efficiency of GUHA Is that through indicators, the other two could be consider as supplementary. Indicators estimate and measure outputs, using qualitative and quantitative information and data, that since were classified, analyzed and weighted, then are converted to well-structured indicators.

6 . There are significant margins for reducing fix and variable costs, maybe up to $15-20 \%$, if some smart upgrades take place like, improving and reeducate personnel, restructuring sectors and clinics in order to be produced some greater economies of scale, synergies and complementarities. Also, the lack of moral and money motives to medical and auxiliary staff of every hospital-therefore and GUHA-means low total productivity and, in contrary, if some smart motives would be given to personnel in a meritocracy basis, they will lead to higher productivity and, therefore, to higher total performance, lower operational costs, etc [18] .

\subsection{Using SWOT Analysis}

SWOT analysis is a strategic managerial tool determining the competitive position of an organization, e.g. , it analyses the internal and external environment of the organization. The SWOT analysis can help a health organization, or medical organizations to reshape their operational strategy and develop plans for improving their performance. Many institutes have research the similarities and differences between medical systems of Europeans' countries with or without SWOT analysis [19, 20, and 21]. In this context follows, a SWOT analysis for G.U.H.A.

\subsection{Third tool: Using Porter's Five Forces Analysis}

Besides the G.U.H.A. is a state health organization, it has to operate in a very cost effective way. It means to optimize its all functions in order to minimize operational costs. The Porter's five forces model offers all necessary tools to analyze and investigate all qualitative data and information that determine the performance and effectiveness of G.U.H.A. essentially, it gives an outline of social, technological and economic environment within which the GUHA operates. In other words, the five forces model helps organizations like GUHA to, identify well and precisely the existed possible opportunities and avoid all obvious and hidden threats in order to succeed the best. The five forces 


\section{E. Stathakis, K. Brachos, Ch. Abatzianis, D. V. Bandekas and S. G. Mouroutsos/}

Journal of Engineering Science and Technology Review 10 (2) (2017) 141-149

can be summed up as follows 1)intensity of competitive rivalry among public and private health providers, 2) threat of new entrants, e.g. new private health providers, 3) threat of substitute services by new private health providers 4) bargaining power of patients. E.g. to have many choices, other private health providers being much better in cost and quality basis, and 5) bargaining power of suppliers-health providers, in the sense to do cartel.

\section{The threat of new entrants, or new private health providers}

Generally, the health system in Greece does not operate under full competition regime. However today in practice, Greek public hospitals face hard competition by new private health providers. For example, a new private hospital unit established in Alexandroupolis, could offer similar health services in lower cost and higher quality, since it will operate more flexible, with smart economies of scale, using better biomedical equipment, with less administrative staff, better allocation of doctors, etc.

\section{The bargaining power of the suppliers}

The hospital's suppliers essentially supply it with medical materials, medication, and maintenance of medical devices and biomedical equipment. The more suppliers, the better prices, since competition operates much better. The bargaining power of suppliers of the hospital is restricted by some state principles. Also, there are many other limitations like, long-term agreements and contracts between hospital and suppliers, non approval provisions based on life cycle cost basis, etc.Finally, this way of provisions represents one of the fundamental particularities of the health sector in comparison with other fully competitive markets.

\section{Intensity of competitive rivalry}

The rate of competitiveness of the GUHA is extremely low. Until now, non other strong and modern private hospital operates, either in the wider area of Alexandroupolis, or in two bordered countries. In other words, the GUHA operates almost such a monopoly, since patients have no other choice. As the regional health system is structured today, it is very difficult private investors to invest huge amount of money in health organizations, providing healthcare services in lower cost and higher quality, for population economies of scale.

\section{The bargaining power of buyers}

In the case of GUHA, buyers are the total patients. The patients don't have probably strong bargaining power, because, in one hand, the health is special issues without any ability for postpone and the other hand, patients cannot estimate the kind of their illness, due to don't have the necessity knowledge. Also, in the most cases, patients are not price sensitive, since the hospitalization cost is covered by their insurance funds. It should be noted that today, for difficult and scarce diseases, patients are compelled to use very specialized private hospitals, paying very high cost.

\section{Threat of substitute services by new private health providers}

Health in individual level is something great and every patient does everything, regardless the cost, in order to be healed. But health care as system, will must be costeffectively and to offer high quality health services in proper cost in order to be competitive. Of course, all healthcare systems around the world are coming under increasing pressure, due to rising of operational costs. So, a hospital is a part of the health system and, therefore, it will face ever the risk of real, or potential competitors, which would offer the similar, or better health services, in best quality and price. It means, every health organization, belonging to a health system, will have to operate very competitively.

\section{Discussion}

\subsection{A general approach to subject}

Firstly, G.U.H.A. should focus in patient satisfaction. The medical organizations and hospitals should give particular attention in patient satisfaction for ensuring their financial viability [22]. Channeling patients to the afternoon clinics is a tactic which can improve patient satisfaction. In case of G.U.H.A in evening clinics must continue exist the most experienced medical staff as well as the average time per examinations should be increased.

In addition, G.U.H.A should improve its collaboration with the medical school of Alexandroupolis, as well as with the other departments of university in wider area. The hospital should join in more research projects with the academic community. Also there is the necessity for establishment partnerships with other -public and privatemedical centers or research organizations. A medical network -or a cluster - could be developed the brand name of the area as a region which offers high quality medical services.

Additionally, there is the emergency need of integrating in the operation of G.U.H.A business plans for the next 5 or 7 years and setting specific goals. These goals should be established according to the SMART framework. In other words, the objectives should be very specific, measurable, achievable and relevant. Moreover, business plans should focus on Innovation and smart resources management. Apart from the business plan the administration of G.U.H.A. should be subjected to internal and external evaluations concerning its operation at regular intervals, in terms of the macro- as well as the microenvironment (SWOT analysis) but also to other more complex analysis and econometric methods for measuring its effectiveness and productivity as Data Envelopment Analysis (D.E.A.).

Within the context of a DEA analysis, it is common to compare methods and statistical results among two or more hospitals. Therefore, DEA framework needs the twinning of hospital units. Hospitals divisions of GUHA should be "twinned" with similar hospital of other areas or/and countries of Europe with aim the comparison of their structure, operation, efficiency, use of resources and medical and nursing services output. Through symposiums and conferences, the directors, managers, doctors and nurses could exchange ideas and views about similar problems and common strategies and tactics.

\subsection{Introducing modern managerial tools in G.U.H.A. 4.2A. ERP system}

G.U.H.A which employs more than 1200 people, receives more than 42,423 patients per year, with 54 departments, is considered as a typical example of a large health care organization which should operate based on an ERP system. ERPs give the ability of use of shared databases (through servers) in real time which are online. Computers from all the departments of the hospital are connected to a common network, allowing the efficient processing of information and data. Figure 4 illustrates a simple ERP operation structure for G.U.H.A. [23] 


\section{E. Stathakis, K. Brachos, Ch. Abatzianis, D. V. Bandekas and S. G. Mouroutsos/}

Journal of Engineering Science and Technology Review 10 (2) (2017) 141-149

As shown in figure 4, all clinics have access to the information database and in the same time they will keep it updated. This information will concern the patient's history, therapy protocols, etc. At the same time, all of the departments of the hospital -such as staff department, finance department, warehouse etc.- have access to this database. The ERP system will reduce bureaucracy and it will improve its internal processes affecting positively patient satisfaction. Additionally, ERP will allow the immediate exchange of information among doctors concerning patient history, past treatments etc. [24,25].

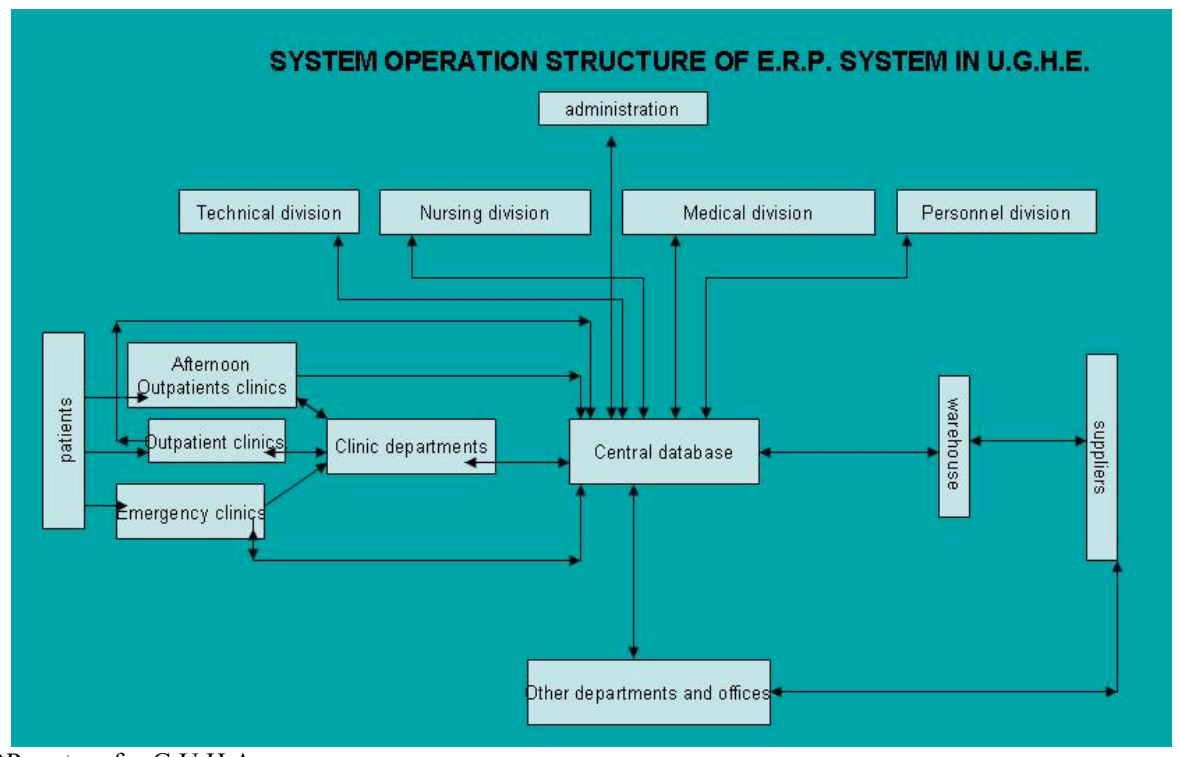

Fig. 4. A proposed ERP system for G.U.H.A.

\subsection{B New biomedical equipment}

Technologies supporting health systems are essential for a cost effective hospital health system. Biomedical devices are critical for the prevention, diagnosis and treatment of illness and disease, and to restore patient [26]. Since, the G.U.H.A. needs new biomedical equipment and better exploitation of the existed one, the hospital's top management will have to put in force a new task force dealing with the next: to evaluate in everyday basis the health technologies and whether they contribute to hospital's cost effective operation, to estimate the needs for medical devices, to optimize in cost and time basis the maintenance of medical equipment through a computer maintenance management system and to deal with innovation, research and development in medical devices. Also the MIS will have to: record and archive of medical equipment with full file management of medical devices, manufacturers, suppliers, teams, models, etc, acquisition procedures for medical Equipment monitoring markets from application to control acceptance, quality assurance using quality and cost indicators for monitoring every activity of GUHA, Publication of reports analyzing data and information. These reports are either defined by the system or can be created by the user according to his needs, management of adverse events with issuing reports to the competent authority, etc.

\subsection{New organizational and operational structure.}

From the middle of last century, a number of the western world advanced countries began to reform their hospital health systems-Greece somewhat later, firstly with the restructuring of their organizational and operational structure, secondly with the introduction of health economics and cost/accounting systems and MIS. This need came because of the effort of restraint the hospitals' administrative and operating costs-the costs increased by geometrical progress overtime, since aged people, as portion of the total one, were increased year by year- doing them much more cost effective health units. At the same time, they increased their research efforts, not only on the structure of operating costs of the hospitals, and for determining specific factors, which added greater cost than benefits, idle beds, drags waste, etc. For university hospitals, like GUHA, a special factor adding cost is the process of training the future medical and nursing staff of the medical school. Fitzgerald and his colleagues confirm that the university hospitals are very complex organizations and, therefore, their structure must be lean, simple but very costeffective in technical and economic basis. The GUHA top management has to deal with this issue very seriously.

\subsection{Enforcing factors/drivers for partnerships and networking}

Factors that can drive the development of high added value cooperation, synergy and networking of G.U.H.A. are the next:

-The quality and cost of medical services offered, this cost has to be very competitive internationally. Many improvements have to be taken place

-The existence of specialized well-skilled medical and nursing staff so that GUHA can faces very difficult patients' cases. Many improvements have to be taken place

-Marvelous external environment, good climate in general, good infrastructure, high quality services offered, famous historic and cultural heritage. It is a fact and therefore it simply has to be communicated more effectively.

-The organizational structure and administrative adequacy to cope with emergency cases. Many improvements have to be taken place

-The ever improving quality of health services provided by GUHA since the GUHA has to compete several other hospitals. A cooperation with other hospitals located in reach countries aiming to exchange best practices and patients is a good strategy. --Doctors and other staff has to be able to 


\section{E. Stathakis, K. Brachos, Ch. Abatzianis, D. V. Bandekas and S. G. Mouroutsos/}

Journal of Engineering Science and Technology Review 10 (2) (2017) 141-149

move and exert their scientific properties around the world, promoting so that the good-will of GUHA. -GUHA has to be charted by international certification standards for its healthcare facilities and biomedical equipment.

-Active participation to social media. The Internet is today the dominant medium in which people seek information on health and health care issues.

-The increase in life expectancy translates into greater healthcare needs, so the development of a new geriatric division probably is a very smart opportunity for GUHA.

- Increase of cooperation with some private providers of health services, since governments are struggling with the pressure caused by underfunding health services. Also GUHA has to seek some special insurance products that provide low cost security packages but for thousand people ensuring serious economies of scale.

\subsection{E New division dealing with E.U projects regarding innovation and $R \& D$ issues}

The mechanisms by which innovation in health sector planned, implemented and exploited, differentiate sometimes from other organizations, enterprises, corporations, etc. The provision of health care is a particularly interesting field to explore the development new drugs, new therapy methods and new biomedical technology for a number of reasons. These reasons can be grouped into 2 broad assertions 1 . Medical innovation often occurs differently than in other areas, because of the emotional factors connected with the concept of health and disease, but and political commitment to offer citizens the latest developments in medicine 2 . Innovative methods have two aspects in biomedical technology - on the one hand, meet the promise of better health and improved quality of life, and, on the other, are associated with higher cost of services. In the context of limited resources and efforts to reduce expenditure, policy makers in the health sector must identify the priorities. Consequently, some new treatment methods, drugs and technologies are diffused, while others do not. The new GUHA office deal with innovation issues will have to do many. To see who will be involved in innovation what determines innovation in medical devices already used in hospital, which are the stages to the process of innovation, which are the trends in the development new drugs, new therapy methods and new biomedical technology products, which are the obstacles for that, etc. GUHA innovation office will have to bridge the gap in availability, suitability and the acceptability of every innovation in order to manage and protect patients.

\section{Final Conclusions.}

The new concept in production, demand and supply of hospital health services, based on strengthening the operational links between the different levels of health units-usually 3 levels- and the convergence of health services with those of social Care, feeds multiple changes up to upsets to both, in the traditional operation models of health systems and in the modern health management models. The horizontal policies, developed to manage the major problems of modern hospital health systems map, the multi-diseases and population aging, cause serious transformations and variations in the operation of the hospital system, but also the new critical
Role they are to undertake healthcare managers and professionals. A healthcare service most certainly constitutes a public good and not merely a consumer good that can be subject to ordinary marketing strategies. There have been eager advocates of the idea of the complete privatization of Health care and others supporting the idea of the absolute state interventionism and control within the health system. However, in most of the counties of the western world none of the two concepts is fully applied. In contrast, a combined health system is implemented which preserves a balance between private and public sector.

One strategy, which can help the health system to remain public, is the highest possible utilization of management approaches, which focus on the measurement of efficiency and productivity of the health care units. Since the country is in its eighth year of recession, which results in the implementation of policies of balanced budgets and cuts in public spending, the issues of efficiency and productivity obtain growing importance.

Regarding GUHA, the analysis revealed that the output of the hospital is in general terms high despite the fact that its personnel decreased in 2013. Additionally, it was found that the hospital is not operating under optimal efficiency and utilization of its incoming resources and that in part is due to the relatively low hospital's occupancy rate and to the fact that its operation and organization structure needs further improvements. Furthermore, in UGHE there are departments with a small number of beds which require a relatively large number of doctors. This results in the underemployment of the medical staff.

Besides, the analysis revealed that the mobility of the patients in the hospital in 2013 was 102,845 which resulted in an annual income of 514,225 Euros due to the charge of 5 Euros. In the same length, the annual income for GUHA from the afternoon outpatient clinics was 355,287 Euros. Thus, coordinated attempts should take place for channeling the patients from the morning outpatient clinics to the afternoon outpatient clinics, in order to increase the revenues of UGHE. Additionally, the token sum of 5 Euros should not be reduced because it constitutes a significant source of incoming resources for the hospital.

In the context of the current analysis, there are several recommendations for future research. Firstly, a future study can compare the effectiveness, the productivity and the efficiency of G.U.H.A with the performance of other hospitals. This comparison will give a clearer picture regarding the operation status of public hospitals in Greece. Besides, other studies can distribute questionnaires to the patients of G.U.H.A, for measuring their satisfaction, as well as the key problems that they faced during their statement in the hospital. Lastly, future studies can use also other indicators which were are not mentioned in the current paper for examining the issues of productivity, efficiency and effectiveness.

The present work is result of M.Sc. Thesis which undertaken in M.Sc. in innovation in Technology \& Engineering Management of Eastern Macedonia and Thrace Institute of Technology.

This is an Open Access article distributed under the terms of the Creative Commons Attribution Licence

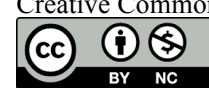




\section{References}

1. Caglar S. Aksezer et all, 2010, “Assessing the efficiency of hospitals operating under a unique owner: a DEA application in the presence of missing data“, International Journal of Services and Operations Management.

2. Brenda Gannon, 2006, "Testing for Variation in Technical Efficiency of Hospitals in Ireland", the Economic and Social Review.

3. Arno Tausch et all, (2012), "A globalization - oriented perspective on health, inequality and socio-economic development".

4. Valdmanis, 1990, "Ownership and Technical Efficiency of Hospitals" Medical Care.

5. Matthias Staat, 2007," Efficiency of hospitals in Germany: a DEA-bootstrap approach", Applied Economics.

6. Y A Ozcan, 1993, "A national study of the efficiency of hospitals in urban markets". Health Serv Res. (HSR).

7. Minwir Al-Shammari, (1999) "A multi-criteria data envelopment analysis model for measuring the productive efficiency of hospitals", International Journal of Operations \& Production Management, Vol. 19 Iss: 9, pp.879 - 891.

8. -Jeroen D.H. van Wijngaarden, (2010), "Strategic analysis for health Organizations: the suitability of the SWOT analysis"

9. T. Christiansen, (2002), "A SWOT analysis of the organization and financing of the Danish health care system", Elsevier.

10. -Bruce Hollingsworth, 2003, "Non-Parametric and Parametric Applications Measuring Efficiency in Health Care", Volume 6, Issue 4, pp 203-218, Health Care Management Science.

11. -Marilyn M. Helms et.all, (2008), "Information Technology (IT) and the healthcare industry", Medical informatics: concepts, Methodologies, tools, and applications, USA

12. Aletras V, Kontodimopoulos N, Zagouldoudis A, Niakas D. (2007): The Short-term Effect on Technical and Scale Efficiency of Establishing Regional Health Systems and General Management in Greek NHS Hospitals, Health Policy, vol. 83, pp.236-245.

13. Farrell M. J. 1, (1957). "Measurement of productive Efficiency", article published by Royal statistical society, Series a, Vol. 120, No.03. , pp 253-290.

14. W.H.O. (2002). Health Service in Europe, $3^{\text {rd }}$ regional office for Europe, Copenhagen.
15. Social determinants of health. Geneva, World Health Organization, 2008 (http://www.who.int/social determinants/en/, accessed 29 April, 2011).

16. Liaropoulos L., (2005). "The selfish of E.S.Y", book published by "medical publics", pp 202-209, Athens.

17. Souliotis (2003). The principals of individual sector in healthcare system, book published by Papazisi, Athens.

18. Souliotis (2003). The principals of individual sector in healthcare system, book published by Papazisi, Athens.

19. Polyzos, N., Karakolias, S., Dikeos, C., Theodorou, M., Kastanioti, C., Mama, K., Polizoidis, P., Skamnakis, C., Tsairidis, C. and Thireos, E. (2014). The introduction of Greek Central Health Fund: Has the reform met its goal in the sector of Primary Health Care or is there a new model needed? BMC Health Services Research, 14(1), p.583.

20. Ng, G., Leung, G., Johnston, J. and Cowling, B. (2013). Factors affecting implementation of accreditation programmes and the impact of the accreditation process on quality improvement in hospitals: a SWOT analysis. Hong Kong Med J, 19(5), pp.434-446.

21. Van Wijngaarden, J., Scholten, G. and van Wijk, K. (2010). Strategic analysis for health care organizations: the suitability of the SWOT-analysis. Int J Health Plann Mgmt, 27(1), pp.34-49.

22. Sharma, M. and Bhatia, G. (1996). The voluntary community health movement in India: A strengths, weaknesses, opportunities, and threats (SWOT) analysis. Journal of Community Health, 21(6), pp.453-464.

23. Griffith, J., R., White, K., R. (2002). The Well Managed Healthcare Organization, $5^{\text {th }}$ ed. Chicago: AUPHA, Health Administration Press.

24. Davenport T. H., (1998). "Putting the enterprise into the enterprise system", USA

-Marius Brostrom et all, (2011), "Translating visions of transparency and quality development: the transformation of clinical databases in the Danish hospital fiel.

24. Everybody's business: strengthening health systems to improve health outcomes: WHO's framework for action. Geneva, World Health Organization, 2009.

25 . Health technology assessment of medical devices. Geneva, W.H.O., 2011 